Pakistan

Minjuan Zhao

China

\title{
Job Crafting Practices and Work Satisfaction: Evidence from Higher Education Sector in Shaanxi, China
}

DOI: 10.15804/tner.2018.52.2.05

\begin{abstract}
We explore the relationships between job crafting approaches (task crafting, relational crafting and cognitive crafting) and work satisfaction among the faculty members of Northwest A\&F University, Yangling, Shaanxi, China. The study reveals a significant and positive relationship between different types of job crafting and work satisfaction. Multiple regression analysis revealed a significant impression of task and relational crafting on work satisfaction but a non-significant impact of cognitive crafting on work satisfaction. Furthermore, the study indicates the importance of job crafting towards a higher level of satisfaction for teachers who are engaged in universities.
\end{abstract}

Keywords: task crafting, relational crafting, cognitive crafting, work satisfaction

\section{Introduction}

Higher education can be considered as the main entity rendering competitiveness to an expanding knowledge-oriented global economy. As higher education systems flourish gradually, the quality of institutes becomes a major concern. In order to determine and encourage effective teaching practices in institutions, efficient evaluation procedures must be exercised. There are several ways by which such an environment can be forged in higher education institutions. Employee satisfaction is one of the prime factors in modern organizations. The most important 
role in an education system is played by the teacher, hence motivating and keeping teachers satisfied is of vital importance as this brings benefits for the whole society.

Dissatisfaction among employees is mainly caused by less control on their professional lives, which hampers their ability to perform well. However, this issue has never been put into red light. Jobs, including teaching, are flexible in nature, which makes them prone to be molded according to the KSAO of job incumbents. Employees can feel more satisfaction by redesigning their jobs so that they utilize their strengths and overcome their weaknesses. It is the concept of job crafting, which allows employees to have control over their professional lives and remain satisfied. Thus, a workforce already in a state of job dissatisfaction can take advantage of job crafting to boost their work engagement and satisfaction (Tims, Bakker \& Derks, 2012).

Job designs provide a meaning to employees' work and the results of that work. Also, they give them a feeling of responsibility for their contributions and their outcomes (Hackman \& Oldham, 1980). Research in this field has shown that job designs can serve as a starting point for an employee to make fundamental alterations for doing tasks and work relationships. Such a kind of changes means job crafting. In other words, job crafting involves re-defining and re-visualizing the design of employees' job according to their personal capacity (Wrzesniewski \& Dutton, 2001).

Job crafting is a kind of activity which is usually undertaken by employees in order to make necessary changes to re-sketch their jobs. It is bottom to top activity, not top to bottom (Wrzesniewski \& Dutton, 2001). Job crafting includes three approaches: task, relational, and cognitive. Task crafting occurs when employees change their routine work duties through adding, changing or ignoring tasks or through changing the time and effort they usually devote to varying tasks. Relational crafting revolves around how employees change their interactions with others while performing their job. Cognitive crafting involves change in employees' perception of the tasks and relationships that constitute their jobs (Berg, Dutton \& Wrzesniewski, 2013).

Literature reveals that crafting for developing job design has not been practiced in institutes or organizations providing higher education. The study is designed to investigate how job crafting impacts work satisfaction. There is no previous research which supports the importance of a specific kind of job crafting and its relationship with different types of job crafting towards job satisfaction. This gap is the focus of the present study. 


\section{Review of past studies}

Previous research on job crafting showed promising results. Pioneers in the field, Wrzesniewski and Dutton (2001), showed how people with jobs having low status made their work meaningful and felt surprisingly positive. According to Tims and Bakker (2010), employees' self-initiated changes are the reason for job crafting that makes employees balance their job demands and resources with their individual needs and abilities. Bakker, Demerouti and Xanthopoulou (2012) found that individuals who were more involved in job crafting were more engaged in work and showed better performance. The more control or freedom individuals had, the more engaged they felt (Petrou et al. 2012; Leana et al., 2009).

In job crafting, physical task margins can be altered by shifting the scope and variety of work exercises, i.e., individuals decide to do more or less diverse tasks than those included in their original job description. Job crafting also involves altering the cognitive task limits, which is linked to shifting the job perception. For example, a sweeper may either view his job as cleaning up or as contributing to the comfort of individuals around. Altering relational boundaries defines modification in the quality and/or the degree of communication with colleagues. For example, an individual may prefer not to interact with less favorite colleagues. By altering these, employees can alter their job-design and surrounding environment at work themselves.

A few researchers have theorized job crafting as employees' proactive behavior which targets job characteristics and frames the Job Demands-Resources Model. It can also be defined as a modification which employees may make to stabilize their workload and related issues with their own skills (Tim \& Bakker, 2010). Wrzesniewski \& Dutton (2001) redifined job crafting from only changing tasks and relations to task crafting and relational crafting. Task crafting is linked to job requirements, i.e., varying one's responsibilities by making the demands more challenging and/or reducing unchallenging needs. Relational crafting is linked to job attributes, i.e., altering the existing social resources.

Petrou et al. (2012) explain job crafting as: (i) looking for contests; (ii) fewer demands; and (iii) looking for resources. Looking for challenges is seeking more challenging demands, i.e., considering new stimulating tasks, making oneself busy all day, or looking for more tasks after completing the already assigned tasks. This is to encourage work motivation and to remove boredom. Workers in dynamic jobs generally achieve success in tough situations, which promotes their learning. Diminishing demands mean lessening expressively or substantially challenging features of one's work to shrink one's capacity, which ensures that work does not 
interfere with one's private life. So, in this way reducing demands is health-protecting coping. Looking for job resources is some sort of covering job needs, or accomplishing duties and attaining ambitions that increase overall well-being and presentation. For instance, asking for response or assistance from bosses or coworkers, or searching for opportunities to use innovative skills. Decreasing resources cannot be considered as a type of job crafting because it does not predict behavior with a purpose (Hobfoll, 2001).

Theoretically, the importance of job crafting has been verified by Petrou et al. (2012), who conducted research on one hundred staff members of different organizations. They observed that job crafting exists every day with fluctuations in job crafting ranging from $31 \%$ (seeking challenges), 34\% (seeking resources) to $78 \%$ (reducing demands). The main difference among the above-mentioned models is that the JD-R framework emphasizes behavioral constituents and eliminates the cognitive extent of job crafting. As a conclusion, the limited research on job crafting clearly proves that job crafting is related to positive employee and organizational outcomes, which include job commitment, performance and gratification.

\section{Study Hypotheses}

The research focuses specifically on the presence of job crafting. It is important to investigate which type of job crafting teachers want to practice more. Thus, the main objective of the present study is to use quantitative methods to explore how the presence of a specific type of job crafting relates to work satisfaction. Figure 1 illustrates the research framework of the present study.

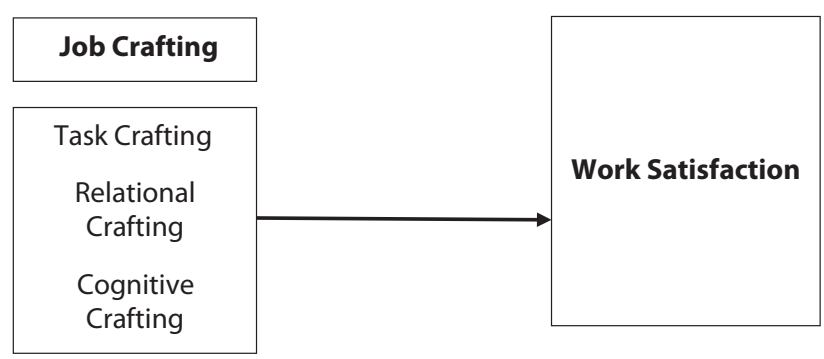

Figure 1. The research framework 
The published material related to job crafting and work satisfaction revealed that three hypotheses were tested (Wrzesniewski and Dutton, 2001). These hypotheses are the following:

Hypothesis 1: The teachers who are engaged in task crafting are satisfied at work.

Hypothesis 2: The teachers who are engaged in relational crafting are satisfied at work.

Hypothesis 3: The teachers who are engaged in cognitive crafting are satisfied at work.

Hypothesis 4: The teachers want to engage in all types of crafting techniques.

\section{Material and Methods}

\subsection{Work Satisfaction Measures}

In order to measure work satisfaction, the Job Diagnostic Survey (JDS), developed by Hackman and Oldham (1976), was used. According to this survey, the obtained scores were summarized into single generic item of work satisfaction. A higher score corresponds to a higher level of satisfaction while a lower score corresponds to a lower level of satisfaction.

\subsection{Job Crafting Measures}

To conduct he survey, a questionnaire was designed to obtain the basic data required to check the influence of job crafting on work satisfaction. Job crafting was tested with the use of a job crafting questionnaire (Slemp \& Vella-Brodric, 2013). It is a recently developed scale, which measures the level of the satisfaction of workers engaged in job crafting. The measured data comprise fifteen items and respondents specify the occurrence through which they want to engage in each of the activities related to job crafting. The scores range from 1 to 6 , from "hardly ever" to "very often" respectively.

\subsection{The Data}

The study was conducted in order to examine which type of crafting has the greatest impact on job satisfaction and find the association between job crafting and satisfaction. Data was obtained through questionnaires, which were provided to the faculty members of different departments of Northwest A\&F University, Yangling, Shaanxi, China. A total of 100 participants were selected. Survey questionnaires were given to 150 teaching staff, comprising lecturers, assistant professors, associate professors and professors. Various methods of communica- 
tion (personal contact and e-mail) were used to get the maximum feedback. The response rate was about 67\% (100 samples) from 150 distributed questionnaires.

\subsection{Characteristics of the Respondents}

One hundred university teachers participated in this study, of whom $75 \%$ were male and 25\% were female. The majority of the respondents were in the 30-39 age category, while the lowest number of respondents belonged to the 50 and above age category. $6 \%$ of the faculty members were 20 to 29 years of age, $43 \%$ were 30 to $39,41 \%$ were 40 to 49 and $10 \%$ were at the age of 50 and over. In terms of qualifications, $4 \%$ held the bachelor's degree, $45 \%$ held the master's degree and $51 \%$, and thus the majority, were $\mathrm{PhD}$ degree holders. The faculty members who participated in this study were selected on the basis of work experience. The benchmark for work experience was one year at least. In terms of experience, 39\% of the faculty had $1-10$ years, $42 \%$ had $11-20$ years, while $17 \%$ had $21-30$ years and only $2 \%$ had 30 years and over.

\subsection{Categorization of Respondents}

Figure 1 presents the percentages of the participants who preferred task crafting, relation crafting or cognitive crafting or a combination of these.

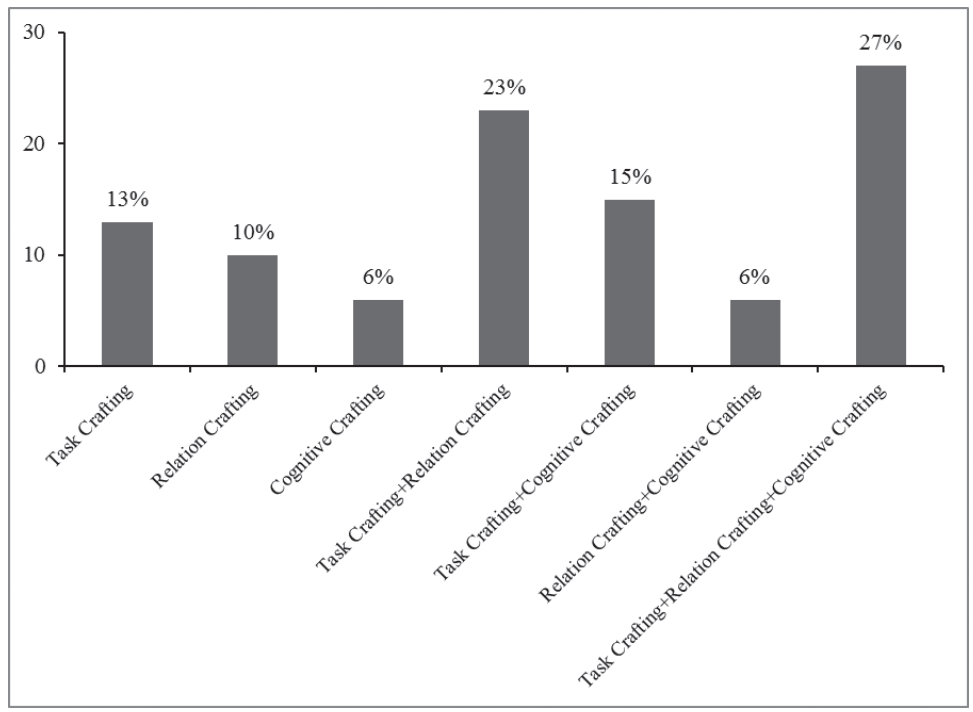

Figure 1. Categorization of respondents according to task crafting, relation crafting and cognitive crafting 
It is clear from Figure 1 that the majority of the teachers (27\%) preferred the combination of all the three types of crafting, i.e., task crafting + relational crafting + cognitive crafting, while there were two groups of teachers (each group consisting of $6 \%$ of the teachers) who preferred relation crafting + task crafting and cognitive crafting, respectively. There was another group of teachers $(23 \%)$ who favored task crafting + job crafting as key factors for job crafting. Moreover, $15 \%$ of the teachers were involved in task crafting + cognitive crafting, $13 \%$ and $10 \%$ of the teachers were engaged in task crafting + relational crafting, respectively. Thus, it can be said that the teachers prefer a multidimensional approach to make their jobs more meaningful.

\section{Results and Discussion}

\subsection{Reliability Analysis}

Prior to testing the hypotheses, it is essential to check test internal consistency and reliability. The Cronbach alpha analysis is the most common measure of internal consistency, whereas a multiple Likert scale is used in a survey. The acceptable reliability coefficient is 0.7 in Cronbach's alpha reliability analysis. Lower thresholds are sometimes used in literature (Nunnaly, 1978).

Task, relational and cognitive crafting consist of five items each and have Cronbach's Alpha of $0.75,0.82$ and 0.77 , respectively. These values indicate a high level of internal consistency for our scale. Table 1 shows the descriptive statistics and a correlation matrix of different job crafting techniques and satisfaction.

\subsection{Hypotheses Testing}

The hypotheses were tested with the use of correlation and multiple regression analysis. All the types of job crafting, i.e., cognitive, relational and task crafting, correlated positively and significantly $(\mathrm{p}<0.01)$ with work satisfaction (Table 1$)$. Although significant correlations were obtained, the magnitude of correlation between task crafting and work satisfaction was stronger than the remaining correlations (Table 1). The correlations among the different job crafting approaches have been found positive and significant except the correlation between relation crafting and cognitive crafting (Table 1).

Table 2 shows that task crafting has a highly significant effect $(\mathrm{p}<0.01)$ on work satisfaction and relational crafting has a significant effect $(\mathrm{p}<0.05)$ on work satisfaction, whereas cognitive crafting does not significantly affect work satisfaction. Thus, hypotheses 1 and 2 are confirmed while cognitive crafting had no significant 
Table 1. Correlation between job crafting and work satisfaction $(\mathrm{N}=100)$

\begin{tabular}{lccccc}
\hline \multicolumn{1}{c}{ Variables } & Mean & Std & Worksat & Cogcraft & Relationcraft \\
\hline Worksat & 4.94 & 0.883 & & & \\
\hline Cogcraft & 5.32 & 1.115 & $.258^{\star *}$ & & \\
\hline Relationcraft & 5.13 & 1.215 & $.343^{\star *}$ & .180 & \\
\hline Taskcraft & 4.73 & 1.198 & $.458^{\star *}$ & $.246^{\star}$ & $.309^{* *}$ \\
\hline
\end{tabular}

Std - standard deviation; Worksat - work satisfaction; Cogcraft - cognitive crafting;

Relationcraft - relational crafting; Taskcraft - task crafting

effect on satisfaction (Table 2$)$, but it was positively correlated $(\mathrm{p}<0.01)$ with satisfaction (Table 1). Thus, hypothesis 3 is partially confirmed. Furthermore, the majority of the respondents are interested in practicing all the types of job crafting techniques (Figure 1). Hence, hypothesis 4 is confirmed.

Table 2. Multiple regression results for job crafting and work satisfaction

\begin{tabular}{lcc}
\hline \multicolumn{1}{c}{ Variables } & Beta & t-value \\
\hline Task Crafting & $0.362^{\star \star}$ & 3.864 \\
\hline Relational Crafting & $0.207^{\star}$ & 2.243 \\
\hline Cognitive Crafting & 0.132 & 1.460 \\
\hline R-square & $\mathbf{0 . 2 7 1}$ & \\
\hline Adjusted R-square & $\mathbf{0 . 2 4 8}$ & \\
\hline F & $\mathbf{1 1 . 8 8 1}$ & \\
\hline Sig. F. & $\mathbf{0 . 0 0 0}$ & \\
\hline
\end{tabular}

${ }^{*} \mathrm{p}<0.05 ;{ }^{* *} \mathrm{p}<0.01$

The results of the present study prove the link between the job crafting types and work satisfaction. However, it is important to note that due to the lower response rate, the study sample may have variation towards the contribution in crafting of the teaching faculty we surveyed. In our study, the positive and significant relationship between task crafting and relational crafting with work satisfaction is supported by the earlier findings of Beer et al. (2016). Job crafting is linked positively to work satisfaction and engagement to make jobs more meaningful (Table 1). People can bring different tactics and attitudes to their work even in similar jobs. Individuals who practiced job crafting were more likely to be engaged in and satisfied with their jobs. 
In general, the results confirmed the hypotheses. Based on the magnitude of relationships of task and relational crafting with work satisfaction (Table 1), it is understandable that the teachers who want to practice job crafting are satisfied with their work. In this study, the teachers feel satisfaction when they practice two types of job crafting, i.e., task crafting and relational crafting. They feel satisfied when they change their assigned job responsibilities by adding, changing or avoiding the tasks or the time and effort assigned to different tasks. Furthermore, relational crafting also has an impact on satisfaction (Table 2), though less significant than task crafting (Table 2). The teachers feel good when they involve in changing how, when, or with whom they interact in the process of performing their job duties. It is worth noticing that cognitive crafting does not have any significant impact on satisfaction (Table 2). Tims and Bakker (2010) claimed that cognitive crafting is a type of avoidance coping because individuals adjust their viewpoint on those work conditions that do not meet their needs or preferences instead of really shaping their jobs. The results support this argument. Teachers do not want to alter their perceptions related to their tasks and relationships; rather they want to practice crafting by altering their tasks and relationships in the workplace.

\section{Conclusions and Recommendations}

In sum, the presented study shows very important results which give very useful insights into ways of improving work-related job design in the future. The majority of the teachers working in Northwest A\&F University want to practice task and relational crafting instead of cognitive crafting. Teachers play an important role in society; their job design should be considered important and should be modified in the way that is attractive enough to enhance employee satisfaction. Satisfied teachers will give better output to society.

Therefore, it can be recommended that a job should be designed in such a way that employees are given autonomy where they can easily craft their job to make it more meaningful. Their tasks should be redefined in a way that puts more stress on service and craftsmanship. It can be suggested to human resource departments or concern departments that during designing the jobs, they should consider employees' autonomy so that they can make their job more appealing by altering their jobs when needed. Although work is important for almost everyone for financial support, along with the sacrifices required by work, it can also be interesting to employees. Identifying teachers' attitude towards work can help a human resource department specify what employees require in their professional life and 
let them alter their jobs accordingly to increase their satisfaction. This will in turn increase performance and commitment and reduce absenteeism and the turnover rate.

\section{References:}

Bakker, A.B., Demerouti, E., \& Xanthopoulou, D. (2012). How do engaged employees stay engaged? Ciencia \& Trabajo, 14: 15-21

Beer, L.T., Tims, M., and Bakker, A.B. (2016). Job crafting and its impact on work engagement and job satisfaction in mining and manufacturing. South African Journal of Economic and Management Sciences, 19(3): 400-412

Berg, J.M., Dutton, J.E., \& Wrzesniewski, A. (2013). Job crafting and meaningful work. In B.J. Dik, Z.S. Byrne, \& M.F. Steger (eds.). Purpose and meaning in the workplace (pp. 81-104). Washington, DC: American Psychological Association

Hackman, J.R. and Oldham, G.R. (1976). Motivation through the design of work: test of a theory. Organization behavior and human performance, 16: 250-279

Hackman, J.R. and Oldham, G.R. (1980). Work redesign. Reading, MA: Addison-Wesley. Hobfoll, S.E. (2001). The influence of culture, community, and the nested-self in the stress process: Advancing Conservation of Resources theory. Applied Psychology: An International Review, 50(3): 337-370

Karasek, R. and Theorell, T. (1990). Healthy Work: Stress, Productivity, and the Reconstruction of Working Life. New York: Basic Books

Leana, C., Appelbaum, E., and Shevchuk, I. (2009). Work process and quality of care in early childhood education: The role of job crafting. Academy of Management Journal, 52: $1169-1192$

Nunnaly, J. (1978). Psychometric theory. New York: McGraw-Hill.

Petrou, P., Demerouti, E., Peeters, M.C.W., Schaufeli, W.B., and Hetland, J. (2012). Crafting a job on daily basis: Contextual correlates and the link to work engagement. Journal of Organizational Behavior, 33, 1120-1141

Slemp, G.R. and Vella-Brodrick, D.A. (2013). The job crafting questionnaire: A new scale to measure the extent to which employees engage in job crafting. International Journal of Wellbeing, 3(2), 126-146. doi:10.5502/ijw.v3i2.1

Tims, M. and Bakker, A.B. (2010). Job crafting: Towards a new model of individual job redesign. South African Journal of Industrial Psychology, 36: 1-9

Tims, M., Bakker, A.B., \& Derks, D. (2012). Development and validation of the job crafting scale. Journal of Vocational Behavior, 80: 173-186

Wrzesniewski, A. and Dutton, J.E. (2001). Crafting a job: Revisioning employees as active crafters of their work. Academy of Management Review, 26: 179-201 